certainly have corroborated the findings that TT poudrage is more cost-effective than chest-tube drainage, a well accepted treatment for PSP requiring a chest tube. In other words, our study, performed with a randomised, prospective design, definitely showed that TT poudrage is superior to conservative treatment by chest-tube drainage. This is important information which has never been reported before. SCHRAMEL et al. [1] performed a different study. They compared retrospectively, in two historical series, video-assisted thoracoscopic surgery (VATS) under general anaesthesia to chest-tube drainage alone, as treatment of PSP requiring chest-tube drainage. They showed that the more expensive technique, VATS, was more cost-effective than conservative treatment. The same authors further concluded that using simple talc poudrage would have resulted in an additional $62 \%$ reduction of the cost [2]. A mini-invasive technique, such as thoracoscopy with talc pleurodesis, is very effective in preventing recurrence of a spontaneous pneumothorax either for a first episode of PSP or secondary pneumothorax, even it is an old technique performed for a $100 \mathrm{yrs}$, as suggested by WEISSBERG and REFAELY [3]. We think that in today's standard of care, the patient with a first episode of PSP requiring a chest tube should be offered the choice between a treatment which importantly reduces the recurrence rate (TT), versus a treatment with a higher recurrence rate (pleural drainage), both treatments implying the same duration of hospital stay.

Secondly, we agree that there is ongoing discussion about when and how long to apply suction through the chest tube in either group. Unfortunately, there is currently no answer to this question because of lack of scientific data. We decided to use suction immediately in the TT group because it is performed in this way in all centres participating in the study, based on the idea that the sooner parietal and visceral pleural are brought in contact with each other, the better.

Thirdly, we do not agree with the comment about the method of cost calculation as proposed. Our study was a multicentre European trial conducted in five countries with different health systems and different hospital reimbursement policies. The only economically reliable method to look at the real costs was to unify the method of calculation, after having meticulously recorded all procedures material and manpower used for each patient.

Finally, although it is very easy to insert a second drain under visual control at the end of thoracoscopy, we agree that the same hole can be used for this purpose.

J-M. Tschopp*, C. Boutin ${ }^{\#}$, P. Astoul ${ }^{\#}$, J-P. Janssen ", C-T. Bolliger ${ }^{+}$, L. Delaunois ${ }^{\S}$, P. Driesen ${ }^{f}$, G. Tassi**, A-P. Perruchoud and the European Study on Medical Video-Assisted Thoracoscopy (ESMEVAT) team

*Centre Valaisan de Pneumologie, Montana, Switzerland. ${ }^{\text {\#}}$ Service de Pneumologie, Hôpital de la Conception, Marseille, France. "Afdeling Longziekten, Canisius Wilhelmina Ziekenhuis, Nijmegen, the Netherlands. ${ }^{+}$Abteilung für Pneumologie, Universitätskantonsspital, Basel, Switzerland. ${ }^{\$}$ Service de Pneumologie, Cliniques Universitaires UCL de Mont-Godinne, Yvoir, Belgium. ${ }^{f}$ St Elisabeth $\mathrm{ZH}$, Turnhout, Belgium. **Divisione di Pneumologia, Spedali Civili, Brescia, Italy.

\section{References}

1. Schramel FMNH, Sutedja TG, Braber JCE, van Mourik JC, Postmus PE. Cost-effectiveness of video-assisted thoracoscopic surgery versus conservative treatment for first time or recurrent spontaneous pneumothorax. Eur Respir J 1996; 9: $1821-1825$

2. Noppen N. Treatment of spontaneous pneumothorax - an ongoing debate. Eur Respir J 1998; 11: 514-515.

3. Weissberg D, Refaely Y. Pneumothorax: experience with 1,199 patients. Chest 2000; 117: 1279-1285.

\title{
Carbon dioxide production during acetazolamide and medroxyprogesterone treatment
}

\section{To the Editor:}

WAGENAAR et al. [1] report improvement in gas exchange and increased minute ventilation $\left(V^{\prime} \mathrm{E}\right)$ in patients with stable, moderately severe chronic obstructive pulmonary disease receiving treatment with acetazolamide and medroxyprogesterone. They estimate a baseline carbon dioxide $\left(\mathrm{CO}_{2}\right)$ production rate of $400 \mathrm{~mL} \cdot \mathrm{min}^{-1}$ from the placebo values for $\mathrm{CO}_{2}$ arterial tension $\left(\mathrm{Pa}_{1} \mathrm{CO}_{2}\right)$ of $6.5 \mathrm{kPa}$ or $49 \mathrm{mmHg}$ and $V^{\prime} \mathrm{E}$ of $9.3 \mathrm{~L} \mathrm{~min}^{-1}$. Assuming that $\mathrm{Pa}, \mathrm{CO}_{2}$ can be substituted for alveolar carbon dioxide tension $\left(\mathrm{PCO}_{2}\right)$, one can calculate the dead space to tidal volume ratio ( $V \mathrm{D}: V \mathrm{~T})$ using the standard formula [2]:

$$
P_{\mathrm{a}, \mathrm{CO}_{2}}=0.863 \frac{V^{\prime} \mathrm{CO}_{2}}{V^{\prime} \mathrm{E}\left(1-\frac{V_{\mathrm{D}}}{V_{\mathrm{T}}}\right)}
$$

where $V^{\prime} \mathrm{CO}_{2}$ is carbon dioxide production.

The $V \mathrm{D}: V \mathrm{~T}$ calculates to 0.24 , a surprisingly low value in patients with advanced airways obstruction. If this value is modified by the increased $V \mathrm{~T}$ during acetazolamide and medroxyprogesterone treatment and one calculates $V^{\prime} \mathrm{CO}_{2}$ $\left(P \mathrm{a}, \mathrm{CO}_{2}\right.$ of $5.3 \mathrm{kPa}$ or $40 \mathrm{mmHg}$ and $V^{\prime} \mathrm{E}$ of $\left.11.2 \mathrm{~L} \cdot \mathrm{min}^{-1}\right)$,
$V^{\prime} \mathrm{CO}_{2}$ is $412 \mathrm{~mL} \cdot \mathrm{min}^{-1}$, not the $450 \mathrm{~mL} \cdot \mathrm{min}^{-1}$ the authors state.

If medroxyprogesterone therapy was associated with a substantial increase in metabolic carbon dioxide production, then an increase in total ventilation would be necessary to prevent an increase in alveolar and arterial carbon dioxide tension production, in part defeating the purpose of the use of respiratory stimulants in this situation.

R.P. Cole

Dept of Medicine, Columbia University, New York, USA.

\section{References}

1. Wagenaar M, Je Vos P, Heijdra YF, Teppema LJ, Folgering HTM. Combined treatment with acetazolamide and medroxyprogesterone in chronic obstructive pulmonary disease patients. Eur Respir J 2002; 20: 1130-1137.

2. Staub NC. Basic Respiratory Physiology. New York, Churchill Livingston, 1991; pp. 52-53. 